\title{
A Retrospective Review of Supratherapeutic Modafinil Exposures
}

\author{
Shaun D. Carstairs • Andrew Urquhart • \\ Justin Hoffman • Richard F. Clark • F. Lee Cantrell
}

Published online: 1 April 2010

(C) The Author(s) 2010. This article is published with open access at Springerlink.com

\begin{abstract}
Modafinil is a non-amphetamine wakefulnesspromoting agent used for the treatment of various sleep disorders characterized by excessive daytime sleepiness. There is little information in the medical literature with respect to supratherapeutic doses of this medication. We performed a retrospective review of the California Poison Control System database for all cases of single-substance ingestion of modafinil with follow-up to a known outcome for the time period 1998-2008. Data collected included age, gender, dose ingested, clinical effects, and medical outcome. There were a total of 87 patients, 53 (61\%) of which were female. Patient ages ranged from 1.25 to 72 years with a mean of 30 years; $17(20 \%)$ patients were aged 6 years or less. Thirty-three $(38 \%)$ were intentional overdoses. Most commonly reported effects were tachycardia $(n=23)$, agitation $(n=14)$, anxiety $(n=11)$, headache $(n=8)$, hypertension $(n=6)$, dystonia/tremor $(n=6)$, and dizziness $(n=5)$. Forty-nine patients $(56 \%)$ were managed at home, and 38 (44\%) were managed in a healthcare setting. Therapies administered included activated charcoal $(n=8)$, benzodiazepines $(n=7)$, antihistamines $(n=2)$, intravenous fluids $(n=2)$, haloperidol $(n=2)$, and beta-blockers $(n=1)$. Effects were
\end{abstract}

S. D. Carstairs $(\bowtie) \cdot$ R. F. Clark

Division of Medical Toxicology,

Department of Emergency Medicine, University of California,

San Diego, CA, USA

e-mail: shaunc@yahoo.com

R. F. Clark $\cdot$ F. L. Cantrell

California Poison Control System, San Diego Division,

San Diego, CA, USA

A. Urquhart · J. Hoffman

Skaggs School of Pharmacy and Pharmaceutical Sciences,

University of California,

San Diego, CA, USA classified as none $(n=22)$, minor $(n=54)$, and moderate $(n=11)$. No major effects and no deaths occurred. Effects of modafinil overdose appear to be mild in most cases, with tachycardia and CNS symptoms predominating. Clinically significant effects requiring treatment occurred in a small number of patients.

Keywords Modafinil $\cdot$ Poisoning $\cdot$ Overdose

\section{Introduction}

Modafinil (2-[(Diphenylmethyl) sulfinyl] acetamide) is a unique non-amphetamine wakefulness-promoting agent that was first marketed in France in the early 1990s for the treatment of excessive somnolence in patients with narcolepsy. It was subsequently approved in the USA in 1998 under the brand name Provigil ${ }^{\circledR}$ and is used for the treatment of various sleep disorders characterized by excessive sleepiness, including narcolepsy, obstructive sleep apnea, and shift work sleep disorder. It has steadily gained popularity among prescribers due to its wakefulnesspromoting efficacy, presumed lower potential for abuse, and lack of peripheral sympathomimetic effects commonly observed with amphetamine stimulants. As a result, it has been studied and used off-label to treat sedation and fatigue in neurological and medical conditions including multiple sclerosis [1], Parkinson's disease [2], HIV infection [3], cancer [4], and fibromyalgia [5]. It has also shown promise in the treatment of cocaine dependence and withdrawal [6-8], alcoholic organic brain disorder [9, 10], and in augmentation of antidepressant regimens [11].

Modafinil appears to have a complex mechanism of action that is not completely understood. It is known to cause an increase in extracellular concentrations of dopamine, 
257 modafinil exposures identified

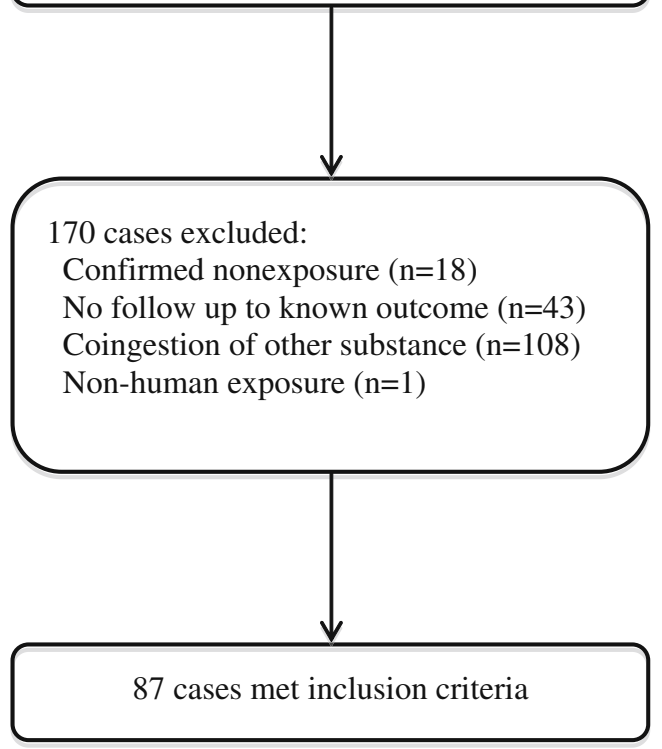

Fig. 1 Flow diagram of identified modafinil exposures

norepinephrine, serotonin, glutamate, and histamine and to cause a decrease in extracellular gamma-aminobutyric acid in the neocortex [12]. It has been shown to bind to and inhibit the dopamine transporter and norepinephrine transporter at clinically relevant doses, which may be responsible in part for its therapeutic effects [13]. Unlike amphetamines, modafinil has no effect on spontaneous dopamine release or turnover and lacks peripheral sympathomimetic effects $[12,14,15]$.

Little information on supratherapeutic dosing of modafinil exists in the current medical literature. Two small case series have been published in abstract form [16, 17], and a recent review of data from 11 states was published by Spiller et al. [18]. During clinical trials, intentional acute overdoses as high as 4,500 mg were reported, with insomnia, tachycardia, agitation, and anxiety being the only side effects reported; no life-threatening toxicity occurred, and to date, no fatal overdoses have occurred involving modafinil alone [19].

We performed a retrospective chart review of modafinil exposures reported to the California Poison Control System over an 11-year period. Our aim in this study was to characterize the clinical effects and toxicity associated with overdose of modafinil in the hope of improving treatment guidelines and recommendations for patients with modafinil ingestion.

\section{Methods}

The University of California-San Diego Institutional Review Board approved this retrospective cohort study. A retrospective chart review of the California Poison Control
System (CPCS) electronic database (Visual Dotlab) for cases between the years 1998 and 2008 was performed. Search codes included the terms "modafinil" and "Provigil." Cases were assessed by the principal and assistant investigators only after removal of all patient identifiers. Inclusion criteria included patients of any age with single substance exposure to modafinil and follow-up to a known outcome (this cohort included patients exposed to modafinil who were described in abstract form in $[16,17])$. Exclusion criteria were history of any co-ingestants and inability to follow the patient to a known outcome.

Data collected included date of occurrence, age, gender, weight (where available), dose ingested by history (or, in the case of a child, pill count or events witnessed by a parent), whether exposure was intentional or unintentional, symptoms, duration of clinical effects, site of exposure, management site, treatment, length of hospital stay, and clinical outcome. Among intentional exposures, "abuse" was defined as use of the medication for purported psychotropic effects, while "misuse" was defined as use of the medication for its known stimulating effects for non-FDA-approved indications (e.g., to facilitate studying). Tachycardia was defined as a heart rate $>100 \mathrm{bpm}$, and hypertension was defined as a systolic blood pressure $>140 \mathrm{mmHg}$ or diastolic blood pressure $>90 \mathrm{mmHg}$. Outcomes were coded as "no effect," "minor effect," "moderate effect," "major effect," or "death" according to the criteria set forth by the American Association of Poison Control Centers [20]. All data abstracted were transcribed into a standardized Microsoft Excel 2008 for Mac (Microsoft, Redmond, WA) spreadsheet.

\section{Results}

A total of 257 cases of modafinil ingestion were reported to the CPCS between 1998 and 2008. Eighteen cases were excluded because of confirmed non-exposure (e.g., all pills were later accounted for), 43 were excluded due to lack of follow-up to a known outcome, 108 were excluded due to reported coingestants, and one was a non-human (canine) exposure. This left 87 cases that met inclusion criteria (see Fig. 1).

Fifty-three patients $(60.9 \%)$ were female. Patient ages ranged from 1.25 to 72 years with a mean of 29.9 years. Seventeen patients $(19.5 \%)$ were 6 years of age or less.

Table 1 Exposure management sites

\begin{tabular}{lc}
\hline Exposure management site & Number of patients (\%) \\
\hline On-site (e.g., home) & $49(56.3)$ \\
Emergency department & $33(37.9)$ \\
Critical Care Unit & $4(4.6)$ \\
Physician's office & $1(1.1)$ \\
\hline
\end{tabular}


Table 2 Summary of medical outcome by dose of modafinil ingested

\begin{tabular}{llll}
\hline & No effect & Minor effect & Moderate effect \\
\hline All patients $(n=87)$ & $22(25.3 \%)$ & $54(62.1 \%)$ & $11(12.6 \%)$ \\
Patients with known dose $(n=81)$ & $22(27.2 \%)$ & $50(61.7 \%)$ & $9(11.1 \%)$ \\
Dose range $(\mathrm{mg})$ & $50-1200$ & $25-16100$ & $400-8,000$ \\
Mean dose $(\mathrm{mg})$ & 411 & 995 & 1,922 \\
Median dose $(\mathrm{mg})$ & 250 & 400 & 1,200 \\
All patients $\leq 6$ years old $(n=17)$ & $11(64.7 \%)$ & $6(35.3 \%)$ & - \\
Patients $\leq 6$ years old with known dose $(n=16)$ & $11(68.8 \%)$ & $5(31.3 \%)$ & - \\
Dose range $(\mathrm{mg})$ & $50-500$ & $25-1,000$ & - \\
Mean dose $(\mathrm{mg})$ & 186 & 275 & - \\
Median dose $(\mathrm{mg})$ & 100 & 100 & - \\
\hline
\end{tabular}

Eighty-one cases (93.1\%) had a reported ingested amount of modafinil. Of these, mean and median doses ingested were 939 and $400 \mathrm{mg}$, respectively, with a range of 25-16,100 mg. Exposure management sites are listed in Table 1; the majority of patients $(56.3 \%)$ were managed in a non-healthcare facility setting.

Effects were classified as no effect $(n=22)$, minor $(n=54)$, and moderate $(n=11)$. No major effects and no deaths were documented. Table 2 shows a summary of medical outcomes by ingested dose. Therapies administered included activated charcoal $(n=8)$, benzodiazepines $(n=7)$, antihistamines $(n=2)$, intravenous fluids $(n=2)$, haloperidol $(n=2)$, and beta-blockers $(n=1)$.

Clinical effects are summarized in Table 3. The most frequently reported effect was tachycardia, which occurred in 23 patients $(26.4 \%)$ and ranged from 101 to $168 \mathrm{bpm}$. Hypertension occurred in six patients $(6.9 \%)$. No cardiac dysrhythmias were reported. There was one report of chest pain in a 65-year-old male who inadvertently took $800 \mathrm{mg}$ of modafinil after mistaking it for acetaminophen; vital signs revealed a heart rate of $64 \mathrm{bpm}$ and blood pressure of $137 / 78 \mathrm{mmHg}$, and troponin measurements were negative.

Neurologic effects following excessive modafinil ingestion also occurred frequently and manifested primarily as agitation, anxiety, and headache. One 37-year-old female accidentally ingested $1,600 \mathrm{mg}$ of modafinil and presented to an ED with agitation, visual hallucinations, and marked orofacial dyskinesia. She was administered lorazepam and diphenhydramine without significant improvement. She was noted to have a heart rate of $115 \mathrm{bpm}$ and blood pressure of $138 / 73 \mathrm{mmHg}$. She was admitted to the intensive care unit where she experienced prolonged dysarthria. She remained tachycardic for $13 \mathrm{~h}$ and was ultimately discharged from the hospital $20 \mathrm{~h}$ post-ingestion without sequelae.

Thirty-three exposures (37.9\%) were intentional. Of these, five $(5.7 \%)$ were due to misuse, while six $(6.9 \%)$ were due to abuse. Ingestions were unintentional in 54 (62.1\%) cases. Of these, 19 were instances where a patient had inadvertently taken a double dose of their medication. Eighteen of these patients had no significant effects; the one symptomatic patient was a 24-year-old female who accidentally ingested $400 \mathrm{mg}$ instead of her usual single $200 \mathrm{mg}$ tablet and who presented to an ED with a heart rate of 168 and blood pressure of $168 / 131 \mathrm{mmHg}$. She was treated with labetalol and was discharged home after a period of observation.

\section{Discussion}

Single-agent exposures to modafinil appear to occur infrequently. In this case series, effects in overdose were usually minor, and significant toxicity occurred only rarely. Specific treatment was required in a minority of patients. Our results are similar to those of the recent study by Spiller et al. [18] which examined data from poison control centers of 11 states. As would be expected, increasing mean and median dosages were associated with more significant clinical effects.

Table 3 Clinical effects

\begin{tabular}{lc}
\hline Clinical effect & Number of patients (\%) \\
\hline Tachycardia & $23(26.4)$ \\
Agitation & $14(16.1)$ \\
Anxiety & $11(12.6)$ \\
Headache & $8(9.2)$ \\
Hypertension & $6(6.9)$ \\
Dystonia/tremor & $6(6.9)$ \\
Dizziness & $5(5.7)$ \\
Insomnia & $4(4.6)$ \\
Stomach upset/nausea & $4(4.6)$ \\
Erythema/flushing & $2(2.3)$ \\
Dysarthria & $2(2.3)$ \\
Hallucinations & $2(2.3)$ \\
Palpitations & $2(2.3)$ \\
Chest pain & $1(1.1)$ \\
Edema & $1(1.1)$ \\
\hline
\end{tabular}


Modafinil has been classified as a schedule IV drug by the Drug Enforcement Administration due to its potential to cause euphoria and alterations in mood, thought, and perception. Although a recent review concluded that modafinil has a low abuse potential [21], a recent volunteer study demonstrated that modafinil increases dopamine concentration in the nucleus accumbens area of the brain, an effect that has been associated with the potential for abuse [22]. Additionally, reports abound in Internet drug use forums of modafinil's misuse among students in order to facilitate studying and improve grades [23]. In our case series, one third (11/33) of intentional exposures were due to abuse or misuse. Given modafinil's increasingly widespread use, it is likely that cases of toxicity will continue to be reported to poison control centers.

Our study has several limitations. This was a retrospective study which limits the amount of data that we were able to retrieve from each case. Some symptoms may have been present but were not reported to CPCS, and our frequency of clinical effects may not represent actual frequency of effects. It is very likely that our study did not capture all cases of modafinil toxicity or exposure, given that reporting of such cases to CPCS is voluntary. Additionally, it is not possible to confirm exposure in all cases since assays for measurement of plasma concentrations of modafinil are not widely available.

Effects seen in our series of modafinil exposures were usually minor, with CNS symptoms and tachycardia most commonly seen. Clinically significant effects requiring treatment did occur in a small number of patients. No significant toxicity occurred with ingestions $<400 \mathrm{mg}$; this suggests that patients who ingest less than this amount may be managed safely at home. Additionally, accidental "double-dosing" of modafinil was not associated with clinical effects in the majority of cases, but did result in clinically significant effects requiring treatment in one patient.

\section{Acknowledgment}

Funding None.

Open Access This article is distributed under the terms of the Creative Commons Attribution Noncommercial License which permits any noncommercial use, distribution, and reproduction in any medium, provided the original author(s) and source are credited.

\section{References}

1. Lange R, Volkmer M, Heesen C, Liepert J (2009) Modafinil effects in multiple sclerosis patients with fatigue. J Neurol 256:645-650

2. Ondo WG, Fayle R, Atassi F, Jankovic J (2005) Modafinil for daytime somnolence in Parkinson's disease: double blind, placebo controlled parallel trial. J Neurol Neurosurg Psychiatry 76:1636-1639
3. Rabkin JG, McElhiney MC, Rabkin R, Ferrando SJ (2004) Modafinil treatment for fatigue in $\mathrm{HIV}+$ patients: a pilot study. $\mathrm{J}$ Clin Psychiatry 65:1688-1695

4. Blackhall L, Petroni G, Shu J, Baum L, Farace E (2009) A pilot study evaluating the safety and efficacy of modafinil for cancerrelated fatigue. J Palliat Med 12:433-439

5. Pachas WN (2003) Modafinil for the treatment of fatigue of fibromyalgia. J Clin Rheumatol 9:282-285

6. Dackis C, O'Brien C (2003) Glutamatergic agents for cocaine dependence. Ann NY Acad Sci 1003:328-345

7. Dackis CA, Kampman KM, Lynch KG, Pettinati HM, O’Brien CP (2005) A double-blind, placebo-controlled trial of modafinil for cocaine dependence. Neuropsychopharmacology 30:205-211

8. Dackis CA, Lynch KG, Yu E, Samaha FF, Kampman KM, Cornish JW et al (2003) Modafinil and cocaine: a double-blind, placebocontrolled drug interaction study. Drug Alcohol Depend 70:29-37

9. Saletu B, Saletu M, Grünberger J, Frey R, Zatschek I, Mader R (1990) On the treatment of the alcoholic organic brain syndrome with an alpha-adrenergic agonist modafinil: double-blind, placebo-controlled clinical, psychometric and neurophysiological studies. Prog Neuropsychopharmacol Biol Psychiatry 14:195-214

10. Saletu B, Saletu M, Grünberger J, Frey R, Anderer P, Mader R (1993) Treatment of the alcoholic organic brain syndrome: double-blind, placebo-controlled clinical, psychometric and electroencephalographic mapping studies with modafinil. Neuropsychobiology 27:26-39

11. Menza MA, Kaufman KR, Castellanos A (2000) Modafinil augmentation of antidepressant treatment in depression. J Clin Psychiatry 61:378-381

12. Minzenberg MJ, Carter CS (2008) Modafinil: a review of neurochemical actions and effects on cognition. Neuropsychopharmacology 33:1477-1502

13. Madras BK, Xie Z, Lin Z, Jassen A, Panas H, Lynch L et al (2006) Modafinil occupies dopamine and norepinephrine transporters in vivo and modulates the transporters and trace amine activity in vitro. J Pharmacol Exp Ther 319:561-569

14. Simon P, Hémet C, Ramassamy C, Costentin J (1995) Nonamphetaminic mechanism of stimulant locomotor effect of modafinil in mice. Eur Neuropsychopharmacol 5:509-514

15. De Séréville JE, Boer C, Rambert FA, Duteil J (1994) Lack of pre-synaptic dopaminergic involvement in modafinil activity in anaesthetized mice: in vivo voltammetry studies. Neuropharmacology 33:755-761

16. Lackey GD, Alsop JA, Albertson TE (2007) A 24 month retrospective study of adult modafinil ingestions. Clin Toxicol (Phila) 45:641 (abstract)

17. Lackey GD, Alsop JA, Sands TR, Albertson TE (2007) A two year retrospective study of pediatric modafinil ingestions. Clin Toxicol (Phila) 45:643 (abstract)

18. Spiller HA, Borys D, Griffith JR, Klein-Schwartz W, Aleguas A, Sollee D et al (2009) Toxicity from modafinil ingestion. Clin Toxicol (Phila) 47:153-156

19. Physicians' Desk Reference (2003) Package insert for Provigil. Thomson PDR, Montvale, NJ

20. Bronstein AC, Spyker DA, Cantilena LR Jr, Green JL, Rumack BH, Heard SE et al (2008) 2007 Annual Report of the American Association of Poison Control Centers' National Poison Data System (NPDS): 25th annual report. Clin Toxicol (Phila) 46:927-1057

21. Myrick H, Malcolm R, Taylor B, LaRowe S (2004) Modafinil: preclinical, clinical, and post-marketing surveillance - a review of abuse liability issues. Ann Clin Psychiatry 16:101-109

22. Volkow ND, Fowler JS, Logan J, Alexoff D, Zhu W, Telang F et al (2009) Effects of modafinil on dopamine and dopamine transporters in the male human brain: clinical implications. JAMA 301:1148-1154

23. Erowid.org. Erowid vault: modafinil (cited 2009 Jun 2). Available from: http://www.erowid.org/smarts/modafinil/modafinil.shtml 